NASATM-86735

NASA Technical Memorandum 86735

NASA-TM-86735

19850021650

\title{
Fault Detection and Accommodation Testing on an F100 Engine in an F-15 Airplane
}

Lawrence P. Myers, Jennifer L. Baer-Riedhart, and Michael D. Maxwell

Jut 181985 


\section{Fault Detection and Accommodation Testing on an F100 Engine in an F-15 Airplane}

Lawrence P. Myers and Jennifer L. Baer-Riedhart

NASA Ames Research Center, Dryden Flight Research Facility, Edwards, California

Michael D. Maswell

Pratt and Whitney Aircraft, West Palm Beach, Florida

\section{N/SA}

National Aeronautics and

Space Administration

Ames Research Center

Dryden Flight Research Facility

Edwards, California 93523 
FAULT DETECTION AND ACCOMMODATION TESTING

ON AN F100 ENGINE IN AN F-15 AIRPLANE

\author{
Lawrence $P$. Myers* and \\ Jennifer L. Baer-Riedhart $\dagger$ \\ NASA Ames Research Center \\ Dryden Flight Research Facility Edwards, CA \\ Michael D. Maxwell* \\ Pratt and Whitney Aircraft, West Palm Beach, FL
}

\section{Abstract}

The fault detection and accommodation (FDA) methodology for digital engine-control systems may range from simple comparisons of redundant parameters to the more complex and sophisticated observer models of the entire engine system. Evaluations of the various FDA schemes are done using analytical methods, simulation, and limitedaltitude-facility testing. Flight testing of the FDA logic has been minimal because of the difficulty of inducing realistic faults in flight. A flight program was conducted to evaluate the fault detection and accommodation capability of a digital electronic engine control in an F-15 aircraft. The objective of the flight program was to induce selected faults and evaluate the resulting actions of the digital engine controller. Comparisons were made between the flight results and predictions. Several anomalies were found in flight and during the ground test. Simulation results showed that the inducement of dualpressure failures was not feasible since the FDA logic was not designed to accommodate these types of failures. In general, the flight results compared well with the ground tests and predictions. The techniques used to induce selected failures in the flight environment were effective in evaluating the FDA $\log i c$.

\section{Nomenclature}

AJ

BUC

$=$ jet primary nozzle area, sq ft

= hydromechanical backup control

CIVV

= compressor inlet variable vane

DEEC

= digital electronic engine control

EPR

= engine pressure ratio, PT6M/PT2

FDA

= fault detection and accommodation

ETIT

= fan-turbine-inlet temperature, ${ }^{\circ} \mathrm{F}$

FTITA

= fan-turbine-inlet temperature. A channel, ${ }^{\circ} \mathrm{F}$

*Propulsion engineer. Member AIAA.

†Project engineer. Member AIAA.

\#Senior test engineer

This paper is declared is work of the U.S.

cowernment and therefore is in Ife motic domain.

\begin{tabular}{|c|c|}
\hline FTITB & $\begin{aligned}= & \text { fan-turbine-inlet temperature, } \\
& B \text { channel, }{ }^{\circ} \mathrm{F}\end{aligned}$ \\
\hline FTITSYN & $\begin{array}{l}=\text { synthesized-fan-turbine-inlet } \\
\text { temperature, }{ }^{\circ} \mathrm{F} .\end{array}$ \\
\hline HP & $=$ pressure altitude, $\mathrm{ft}$ \\
\hline $\mathrm{I} / \mathrm{M}$ & $=$ intermediate power setting \\
\hline LOD & $=$ Iight-off detector \\
\hline M & $=$ Mach number \\
\hline N1 & $=$ fan rotor speed, $\mathrm{rpm}$ \\
\hline NiC & $=$ corrected fan rotor speed, rpm \\
\hline N2 & $\begin{aligned}= & \text { core rotor speed, } \mathrm{rpm} \\
& (100 \% \mathrm{~N} 2=14,000 \mathrm{rpm})\end{aligned}$ \\
\hline $\mathrm{N} 2 \mathrm{C}$ & $=$ corrected core rotor speed, $\mathrm{rpm}$ \\
\hline PB & $=$ burner pressure, $1 \mathrm{~b} / \mathrm{in}^{2}$ \\
\hline PBSYN2 & $\begin{aligned}= & \text { burner pressure synthesized from } \\
& \text { station } 2 \text { pressure, } 1 \mathrm{~b} / \mathrm{in}^{2}\end{aligned}$ \\
\hline PBSYN6 & $\begin{aligned}= & \text { burner pressure synthesized from } \\
& \text { station } 6 \text { pressure, } 1 \mathrm{~b} / \mathrm{in}^{2}\end{aligned}$ \\
\hline PLA & $=$ power lever angle, ${ }^{\circ}$ \\
\hline PS2 & $=$ fan-inlet static pressure, $1 \mathrm{~b} / \mathrm{in}^{2}$ \\
\hline PS2SYN & $\begin{aligned}= & \text { synthesized fan inlet static } \\
& \text { pressure, } 1 \mathrm{~b} / \mathrm{in}^{2}\end{aligned}$ \\
\hline PS6 & $\begin{aligned}= & \text { turbine-discharge static pressure, } \\
& 1 b / \text { in }^{2}\end{aligned}$ \\
\hline PT2 & $=$ inlet total pressure, $\mathrm{lb} / \mathrm{in}^{2}$ \\
\hline PT6M & $\begin{aligned}= & \text { turbin-discharge total pressure, } \\
& 1 \mathrm{~b} / \mathrm{in}^{2} \text { (mixed core and fan stream) }\end{aligned}$ \\
\hline RCVV & $=$ rear-compressor variable vane \\
\hline TT2 & $=$ fan-inlet total temperature, ${ }^{\circ} \mathrm{F}$ \\
\hline WFGG & $=$ gas-generator fuel flow, $1 \mathrm{~b} / \mathrm{hr}$ \\
\hline
\end{tabular}


The detection and accommodation of faults is a vital feature of digital engine-control systems. The methodology for fault detection and accommodation (EDA) may range from simple comparisons of redundant parameters to the more complex and sophisticated observer models of the entire engine system (Refs. 1, 2, and 3). System faults may exist in sensors, actuators, electronics computation, wiring or data links. Detection of these faults may be accomplished by either redundant measurements or synthesized parameters, using either digital and/or analog logic. The accommodation may consist of using redundancy or alternate control modes, inhibiting certain functions, or transferring to a dissimilar control, as discussed in Ref. 1.

The National Aeronautics and Space Administration (NASA), Air Force, Navy and several engine manufacturers are conducting various studies of existing and projected engine-control systems to investigate the capability and performance of various FDA schemes. These studies have made extensive use of analytical methods and simulations. Limited altitude testing in support of these studies has also been accomplished. With the advancement of the full-authority, digital, engine-control systems, and their commitment to production, there has been an increasing need to perform in-flight evaluations of the FDA methodology for substantiating the predictions and facility results of the studies. However, the difficulty of inducing realistic faults in flight has limited flight testing of the FDA logic.

To attempt to satisfy this need, NASA Ames Research Center's Dryden Flight Research Facility has recently conducted the first flight tests in which faults were intentionally introduced into a digital engine-control system. The objectives of the flight program were twofold; first, to introduce selected faults and evaluate the resulting actions of the digital engine controller, and second, to evaluate the concept of in-flight FDA testing.

The FDA testing was accomplished on an F-15 airplane powered by engines equipped with a digital electronic engine control (DEEC) system (Ref. 4). The DEEC is a full-authority, singlechannel digital control with selected redundancy to maintain digital gas-generator control for any single input-output failure. It also incorporates a simple, hydromechanical backup control. The approach used in the FDA testing was not to modify DEEC software and hardware; instead, failures were simulated by interrupting sensor signals with switches and valves. This paper describes the engine, the DEEC, the FDA methodology and logic, flight test techniques and procedures, and flight results.
The F-15 airplane (Fig. 1) is a highperformance, twin-engine fighter, capable of speeds to Mach 2.5. The engine inlets are of the two-dimensional external compression type with three ramps, and feature a variable capture area. The $\mathrm{F}-15$ is powered by two F100-PW-100 engines.

\section{Engine Description}

The F100-PW-100 engine (Fig. 2) is a twinspool, afterburning turbofan with a low bypass ratio $(0.8)$. The three-stage fan is driven by a two-stage, low-pressure turbine. The 10-stage, high-pressure compressor is driven by a two-stage, high-pressure turbine. The engine incorporates compressor-inlet variable vanes (CIVV) and rearcompressor variable vanes (RCVV) to achieve high performance over a wide range of power settings; a compressor bleed is used only for starting. Continuously variable thrust augmentation is provided by a mixed-flow augmentor, which is exhausted through a variable-area convergent-divergent nozzle. The augmentor incorporates five sprayring segments which come on sequentially. Segments 1,2 , and 4 are located in the core stream, and segments 3 and 5 are located in the fan-duct stream.

\section{Engine Control System}

The DEEC is a full-authority, eng ine-mounted, fuel-cooled system that performs the functions of the standard F100 engine's hydromechanical, unified fuel control and the supervisory engine electronic control. The DEEC consists of a singlechannel digital controller with selective inputoutput redundancy, and a simple, hydromechanical backup control (BUC). The DEEC system is shown in Fig. 3. It receives inputs from the airframe through throttle position (PLA) and Mach number $(M)$, and from the engine through pressure sensors (fan-inlet static pressure (PS2), burner pressure $(P B)$, and turbine-discharge static pressure (PT6M)), temperature sensors (fan-inlet total temperature (TT2) and fan-turbine-inlet temperature (FTIT)), and rotor speed sensors (N1 and $\mathrm{N} 2$ ), and the ultraviolet flame sensor (LOD). It also recives feedback from the controlled variables through position-feedback transducers indicating CIVV, RCVV positions, metering-valve positions for gas-generator fuel flow (WFGG), augmentor-core and duct-fuel flow, segmentsequence valve position, and exhaust nozzle position ( $A J)$. Dual sensors and position transducers are used as shown to achieve redundancy in key parameters, such that no single input-output failure will cause loss of digital gas-generator control.

The input information is processed by the DEEC computer to schedule the variable vanes to 
gas-generator and augmentor fuel flows, to position the augmentor segment-sequence valve, and to control exhaust nozzle area.

\section{DEEC Engine Fault-Protection System}

The function of the fault protection system for the DEEC is to provide additional engine safety and operation in the event of an enginecontrol-system failure. It can detect and identify 160 faults within the control system. The FDA logic provides three basic levels of engine operation in the event of an engine-control-system anomaly. The first level maintains normal engine operation with notification that a failure of a redundant parameter has occurred. The second level also maintains normal operation of the gas generator, but inhibits afterburner operation. The third level of accommodation is to automatically transfer control of the engine to the backup control. Afthough the FDA logic uses relatively straightforward methods compared to some of the sophisticated Kalman-Bucy filter methods of Ref. 3, it comprises $40 \%$ of the DEEC control $\log i c$.

\section{FDA Logic}

The DEEC system shown in Fig. 3 incorporates significant fault-detection and accommodation logic. Part of the FDA methodology which is used in the DEEC system is reflected in the amount of redundancy of the system. Dual sensors and position transducers are used to achieve redundancy in key parameters such as engine speeds, temperatures, throttle position, and RCVV. Dual-wound coils are used in the torque motor drivers for all actuators, except the nozzle actuator. Nonredundant, less-critical parameters are pressures, augmentor fuel flow, nozzle area, CIVV, LOD, and aircraft Mach number.

The selective input/output redundancy allows the system to maintain gas-generator control with any single input/output failure. The control detects hard and soft failures of the dual sensors. Hard failures are declared when a sensor exceeds its maximum or minimum expected values. Soft failures are detected when the two signals disagree by more than a predetermined tolerance; the more conservative (safer) sensor value is then used. The pressure sensors PS2, PB, and PT6M are not redundant, but can be synthesized from any one of the other two pressures. Failure of any nonredundant sensor will result in a loss of augmentor capability. Second failures of the dual sensors will trigger an automatic transfer to BUC, as will failures in the DEEC computer internal checks.

\section{EDA Levels}

The three FDA levels in DEEC software are shown in Fig. 4. When the DEEC is operating without faults, the level of FDA activity is normal (represented by the top box of the figure). The next level down occurs when the first fault is detected and one of two possible fault accommodations can take place. One possibility is to accommodate the fault internally in the DEEC processor, and the second is to transfer, to the backup control system. The decision to transfer to BUC is based on one of three possible detected conditions: (1) the DEEC processor has detected a fault which will not allow the processor to control gas-generator fuel flow or schedule RCVV position; (2) the engine-protection logic (overspeed, overtemperature) has detected a variable (N1, N2, or FTIT) that either is over the limit or will reach an over-limit condition at its current rate; (3) an independent fan-speed (N1) logic in the DEEC processor has detected an overspeed.

Other faults at this detection level drop down to the accommodation level if one of four engine operating conditions is selected depending on the fault. The accommodation level which replaces redundant sensor faults one-for-one, gives a normal engine operation. If the fault is within the augmentor control of segments III or IV, these segments are inhibited. If the fault is more inclusive in the augmentor control, then engine augmentation is completely inhibited. If the synthesis of PB is required and a 'like' fault occurs, the DEEC processor automatically transfers engine control to the hydromechanical backup control. Table 1 shows the sensor faults of importance for this paper detectable by the DEEC FDA $\log i c$ and the resulting actions.

\section{Nonredundant sensor $\log$ ic}

The three pressure sensors, PS2, PB, and PT6M are not redundant. The PS2 sensor is used in the fan-speed request, nozzle-area request and trimming, and the engine pressure ratio, PT6M, PT2 (EPR) request and feedback logic. A declared failure of the PS2 sensor causes the DEEC to use a synthesized PS2 based on corrected engine speed, engine inlet temperature, and burner pressure (Fig. 5). In this mode, augmentor and nozzle-area trim functions of the engine are inhibited by the DEEC. In addition, the soft, failure-detection logic for burner pressure is bypassed.

Burner pressure is a critical parameter because it is used in the scheduling of the gasgenerator fuel flow and in the stall detection logic. As with the PS2, detected failures of the $\mathrm{PB}$ cause a synthesized value to be substituted. When the PB is failed, there is no stall detection and augmentation is inhibited. The DEEC processor continuously synthesizes the PB from the PS2, TT2, and corrected core rotor speed, $\mathrm{N} 2 \mathrm{C}$; and also from the PT6M, TT2, and corrected fan rotor speed, N1C (Fig. 5). These two synthesized values are compared to the actual sensed value of the PB. If the three values of $\mathrm{PB}$ are not within predetermined tolerances ( $25 \%$ steady state and $45 \%$ during 
transients and afterburner operation) then the DEEC declares the out-of-tolerance pressure sensor to be failed and substitutes the synthesized value where applicable, either the PBSYN2, PBSYN6, or the PSZSYN.

The PT6M is used primarily at intermediate and afterburner operation as part of the EPR feedback $\log i \mathrm{c}$, augmentor blowout detection and nozzle area trim function. The PT6M is not synthesized because it is used for EPR control which is locked out for any pressure failure, and because detected PT6M failures result in inhibition of the augmentor and nozzle trim functions and bypassing of the $P B$ soft-fail $\log i c$.

\section{Redundant sensor logic}

The critical sensors, TT2, N1, and N2 are dual sensors used by the DEEC. The FDA $\log$ ic searches for redundant sensors which are out of range, and checks agreement between sensors (Fig. 6). If both sensors are in range, the sensors are compared. If the sensors agree, the values are averaged and used. Disagreement between sensors by more than a predetermined tolerance causes the higher, or safer, value to be used. If either sensor is out of range, the inrange sensor is used. If both sensors are out of range, the last in-range value is used and the control transfers to the BUC.

For the FTIT, dual signals are available, but failure of both signals can be accommodated. As shown in Table 1, if both sensors are failed, synthesized FTIT values are used and the maximum allowable value of $\mathrm{N} 2$ is reduced by 1000 RPM.

\section{EDA Test Philosophy}

For the FDA flight test, failures were introduced by interrupting sensor signals upstream of the DEEC, leaving the DEEC's software logic and internal hardware intact. The types of sensor failures induced (such as the PB, PS2, CIVV, and FTIT) would result in engine operation using DEEC synthesized parameters or alternate control modes. Failures in the dual critical sensors could have been introduced, but would have simply resulted in a transfer to the BUC. The sensor fallures were induced to simulate either wires which were broken or pressure lines which were plugged or broken. The dynamic engine-simulation deck was used to analyze the effects of the induced failures at the proposed flight conditions, prior to the ground and flight tests. It was also decided to thoroughly test all proposed failures on a ground-test stand prior to flight.

\section{DEEC FDA Test Schematic}

The DEEC engine was modified to allow switches and valves to be installed on the sensor lines (Fig. 7). The sensor lines that were modified and for which the related FDA logic was evaluated were the PS2, PB, CIVV, and FTIT. The PS2 sensor line was configured to allow the pressure to either be trapped (simulating a plugged line or iced probe) or be ported to another source, PS6 (simulating a broken line). The PB sensor line was configured to allow the pressure to be trapped or dumped to engine-bay ambient pressure (simulating a broken pressure line). Switches were installed in the CIVV feedbackposition transducer wiring and in the Chromel circuit of the FTIT thermocouple circuits to simulate broken wires.

Selection of the failure to be induced was controlled by switches in the cockpit. The configuration of these switches and valves was designed so that normal and fail-safe operation allowed normal DEEC control. No changes were required in the DEEC software, since the faults were induced at the sensors.

\section{FDA Test Conditions}

The test points flown (Fig. 8) were selected to concentrate on the subsonic flight conditions where most of the engine operation occurs. Sensor failures were introduced at steady-state power and during throttle transients. Once the failure had been introduced, the airplane was flown in formation with chase airplanes to evaluate throttleresponse characteristics. Climbs and accelerations were also performed after the failure was introduced. Single failures and combinations of failures were tested.

\section{Test Results}

\section{Simulation results}

A full nonlinear, aerothermodynamic eng ine simulation was used to predict the engine response to the induced failures at both sea-level static and at the proposed flight conditions. Simulations for single failures were first evaluated; then dual failures were evaluated.

The DEEC FDA logic was not designed to accommodate dual pressure failures; however, dualpressure-failure testing was studied. The simulation results showed that for dual pressure (PS2 and $\mathrm{PB}$ ) failures, the engine response could cause an overspeed or an engine stall. If the PS2 is failed soft (high in range) and $P B$ is failed hard, an overspeed potential exists because the synthesized PB is proportional to the PS2, resulting in increased fuel-flow scheduling. The overspeed protection logic was found to be adequate to prevent a catastrophic overspeed, but would in some conditions permit an overspeed that would require maintenance action.

If the PS2 is failed hard, the PB softfailure and stall-detection logic is bypassed; therefore a soft failure would not be detected, and a potentially dangerous situation could 
occur. Based on the simulation results, dual. pressure failures were not evaluated in flight. Simulation results of the other sensor failures (both single and dual) indicated no endangering responses.

\section{Ground test results}

The test engine was installed on a groundthrust stand and all the proposed failures, both single and dual combinations, were evaluated. Failures were induced and evaluated at steadystate power and during throttle transients. Most of the faults were correctly detected and accommodated.

In all cases when the PS2 was failed high in range (by porting it to the PS6), simulating a soft failure, the FDA $\log$ ic did not detect the failure. Pressure failures for the PS2, PB, and PT6M are detected by comparing the sensed and synthesized values of the PB for these pressures. The lack of detection of the PS2 soft failure was found to be a scaling error in the synthesized value of the $\mathrm{PB}$. The $\mathrm{PB}$ was scaled to a maximum value of $600 \mathrm{lb} / \mathrm{in.}$ ? in the DEEC $\operatorname{logic}$, with overscale values wrapped around $\left(601 \mathrm{lb} / \mathrm{in}^{2}\right.$ would erroneously be set to 1 psia, etc.). Therefore, the resulting synthesized value of the $P B$ from the failed high-PS2 signal was wrapped around and was accepted as a good value when evaluated by the FDA logic. For example, at intermediate power the $\mathrm{PB}$ is about $290 \mathrm{lb} / \mathrm{in} .^{2}$; with the failed highPS2 signal, the synthesized PBSYN2 is three times higher than the PB or about $870 \mathrm{lb} / \mathrm{in} .^{2}$. The overscale value would be seen by the DEEC as $270 \mathrm{lb} / \mathrm{in} .^{2}$, resulting in no fault detection of the failed PS2 sensor.

Another anomaly was observed when PB was failed low in range during throttle transients from idle to intermediate by venting the sensor to the engine-bay ambient pressure to simulate a broken pressure line. Figure 9 shows the failure was not detected and the engine decelerated to a subidle condition. Instead of detecting the PB failure, the stall detection logic (based on rate of PB decrease) detected a false "stall." The stall recovery logic reduced the fuel flow so much the engine decelerated to a subidle condition. The engine would not recover or respond to throttle at this condition and had to be shut down and restarted. The stall detection and recovery logic action was activated to correct the "stall" detected by the failed sensor. The failed sensor had not been detected because the transient tolerance of $45 \%$ between the synthesized and sensed values had not been reached prior to the stall being detected.

The FTIT A and B signals were failed, both separately and at the same time. When both channels were failed (by opening the switches in the thermocouple circuit), the internal FTIT driver circuit would either drive the signal to 0 or full scale from the last good value depending on whether the engine was at steady state or in a transient condition. In either case, the FDA $\log$ ic detected and accommodated the failure.

Except as discussed above, the single and dual combination failures were properly detected and accommodated, and agreed with the simulation predictions.

\section{Flight test results}

In-flight failures were introduced at steadystate conditions and during throttle transients. Throttle transients were performed by inducing the failures before and during the throttle movement. Both single and dual failures were evaluated. In most cases, the failures were detected and accommodated.

Figure 10 shows a time history of fan speed for an idle-to-intermediate power throttle transient, first with a normally functioning engine, and then with a failed burner-pressure signal, at a Mach number of 0.8 and an altitude of $20,000 \mathrm{ft}$. The failure was not immediately detected because the failed PB signal was within the $45 \%$ transient tolerance band in the EDA logic. When the FDA logic switched to the steadystate $25 \%$ tolerance, the logic detected the morethan-25\% error, declared the PB sensor failed, and, using PBSYN2, accelerated the eng ine to intermediate power. The engine-dynamic simulation of a failed burner pressure is also shown and matches the actual engine response fairly closely.

Figure 11 shows an intermediate power climb from 5000 to $30,000 \mathrm{ft}$ with PS2 failed (pressuretrapped) at $5000 \mathrm{ft}$ to simulate an iced probe. The failure was undetected until an altitude of 25,000 ft, when the error between PB and PBSYN2 reached $25 \%$. This is more graphically shown in the difference between actual PS2 and failed PS2 values in Fig. 11. Use of the failed PS2 pressure in the control logic during the climb resulted in higher-than-normal EPR and lower-than-normal fanstall margin, but no engine problems were noted.

Figure 12 shows a CIVV failure at $20,000 \mathrm{ft}$ and 0.8 Mach number. The failure was induced during a throttle transient from idle to intermediate and was detected and accommodated by operating the gas generator with the CIVVs in the full cambered position. This results in a lower fan pressure ratio, hence the lower PB. Again, the engine dynamic simulation matches the engine response reasonably well.

Figure 13 shows the effect of a failure of both FTIT sensors at Mach 0.8 and an altitude of $20,000 \mathrm{ft}$. The FDA $\log i \mathrm{c}$ detected the failure and used FTITSYN to monitor FTIT during the snap throttle transient from idle to intermediate power. The maximum upper N2 limit was reduced by $1000 \mathrm{rpm}$ but was not a factor at this flight condition. 
Figure 14 shows that PS2 falled high in range during a maximum-power aircraft acceleration from $0.8 \mathrm{M}$ to $1.35 \mathrm{M}$. In this case PS2 was not detected as being failed because the error between PB and PBSYN2 did not reach the $45 \%$ tolerance allowed during afterburner operation. In fact, the engine was downtrimming EPR (opening the nozzle) to compensate for the false PS2 signal resulting in the engine thrust being much lower than normal. The open nozzle was predicted by the engine-dynamics simulation, but the resulting FTIT was considerably lower than the simulation prediction.

Once the sensor failures were detected and accommodated, the aircraft was flown in close formation with another aircraft to evaluate engine response and handling with known sensor

failures. Pilot comments were favorable; in many instances, the engine response was essentially unaf'fected.

The concept of in-flight FDA testing was verified. No problems or safety hazards were encountered during the four-flight evaluation.

\section{Concluding Remarks}

An evaluation of the fault-detection and accommodation capability of a digital electronic engine control (DEEC) system has been completed at NASA Ames-Dryden. The DEEC was installed on an F100 engine in the Ames-Dryden F-15 airplane.

Engine operation with the DEEC synthesized parameter modes was accomplished over much of the F-15 flight envelope, thereby adding support to the DEEC FDA concept.

Some failures were not detected because of a logic error which was not found immediately. The lack of detection was found to be a scaling error in the synthesized value of PB.

Based on the engine dynamic simulation results, dual pressure failures were not evaluated in $f l i g h t$ because of the potential for engine overspeed and stall. The DEEC FDA logic was not designed to accommodate dual pressure failures.

When P.B was failed low to simulate a broken line, the failure was not detected. Instead the stall detection $\log$ ic detected a false stall, resulting in the engine decelerating to a subidle condition.

In general, the single and dual combination failures agreed well with the engine dynamic simulation predictions. In some cases, pressure sensor failures were not detected because of the large tolerance allowed between synthesized and measured values; this did not result in hazardous engine operation.

Once failures were detected, engine operation with the synthesized parameters was excellent.
Pilots flying in close formation found the engine response to be essentially unchanged. Overall, the in-flight FDA test concept worked well in this first flight evaluation.

\section{Reference}

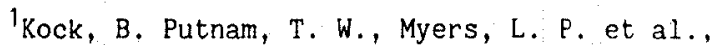
"Digital Electronic Engine Control (DEEC) Flight Evaluation in an F-15 Airplane," NASA CP-2298, Mar. 1984.

${ }^{2}$ Linebrink, K. L. and Vizzini, R. W., "Full Authority Digital Electronic Control (FADAC) Augmented Fighter Engine Demonstration," SAE paper 821371 , Oct. 1982.

3 Beattie, E. C., LaPrad, R. C., Akhter, M. M., and Rock, S. M.: "Sensor Failure Detection for Jet Engines - Final Report," NASA CR-168190, May 1983.

4Myers, L., Mackall, K., and Burcham, F. W. Jr.: "Flight Test Results of a Digital Electronic Engine Control System in an F-15 Airplane," AIAA Paper 82-1080, June 1982. 
Table 1 DEEC Fault Accommodation Summary

\begin{tabular}{|c|c|c|}
\hline Fault-Induced & Failure & Action \\
\hline CIVv & Out of range & $\begin{array}{l}\text { CIVV goes full } \\
\text { cambered }\left(-25^{\circ}\right) \\
\text { augmentation } \\
\text { inhibited, AJ } \\
\text { trim inhibited }\end{array}$ \\
\hline FTITA, FTITB & $\begin{array}{l}\text { Out of range } \\
\text { Soft in-range } \\
\text { A \& B out of } \\
\text { range }\end{array}$ & $\begin{array}{l}\text { Use in-range } \\
\text { sensor } \\
\text { Use higher } \\
\text { sensor } \\
\text { Use calculated } \\
\text { FTIT, N2 } \\
\text { maximum } \\
\text { reduced } 1000 \mathrm{rpm}\end{array}$ \\
\hline 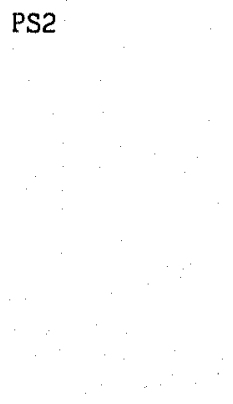 & Soft in-range & $\begin{array}{l}\text { AJ trim } \\
\text { inhibited, } \\
\text { augmentation } \\
\text { inhibited, PB } \\
\text { soft failure } \\
\text { detect bypassed, } \\
\text { PS2SYN } \\
\text { substituted for } \\
\text { PS2. If PB also } \\
\text { failed, transfer } \\
\text { to BUC }\end{array}$ \\
\hline PB & Soft in-range & $\begin{array}{l}\text { PBSYN2, } \\
\text { (calculated) } \\
\text { substituted for } \\
\text { PB, augmentation } \\
\text { inhibited, stall } \\
\text { detect logic } \\
\text { bypassed. If } \\
\text { PS2 also failed, } \\
\text { transfer to BUC }\end{array}$ \\
\hline
\end{tabular}




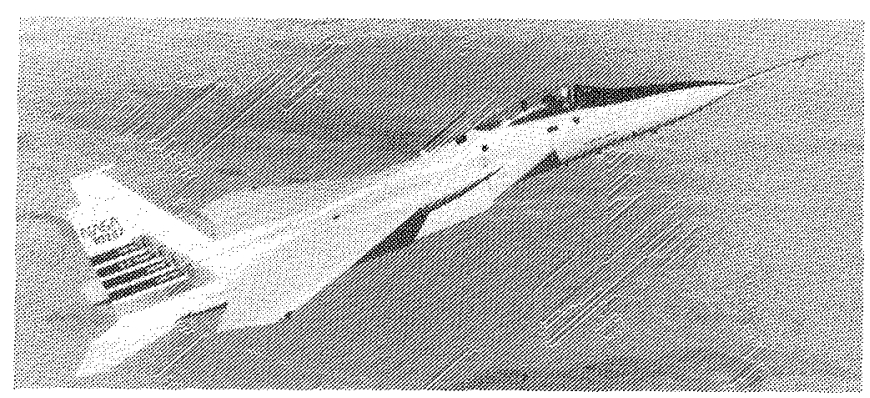

ECN 17691

Fig. 1 The F-15 airplane used for DEEC FDA flight evaluation.

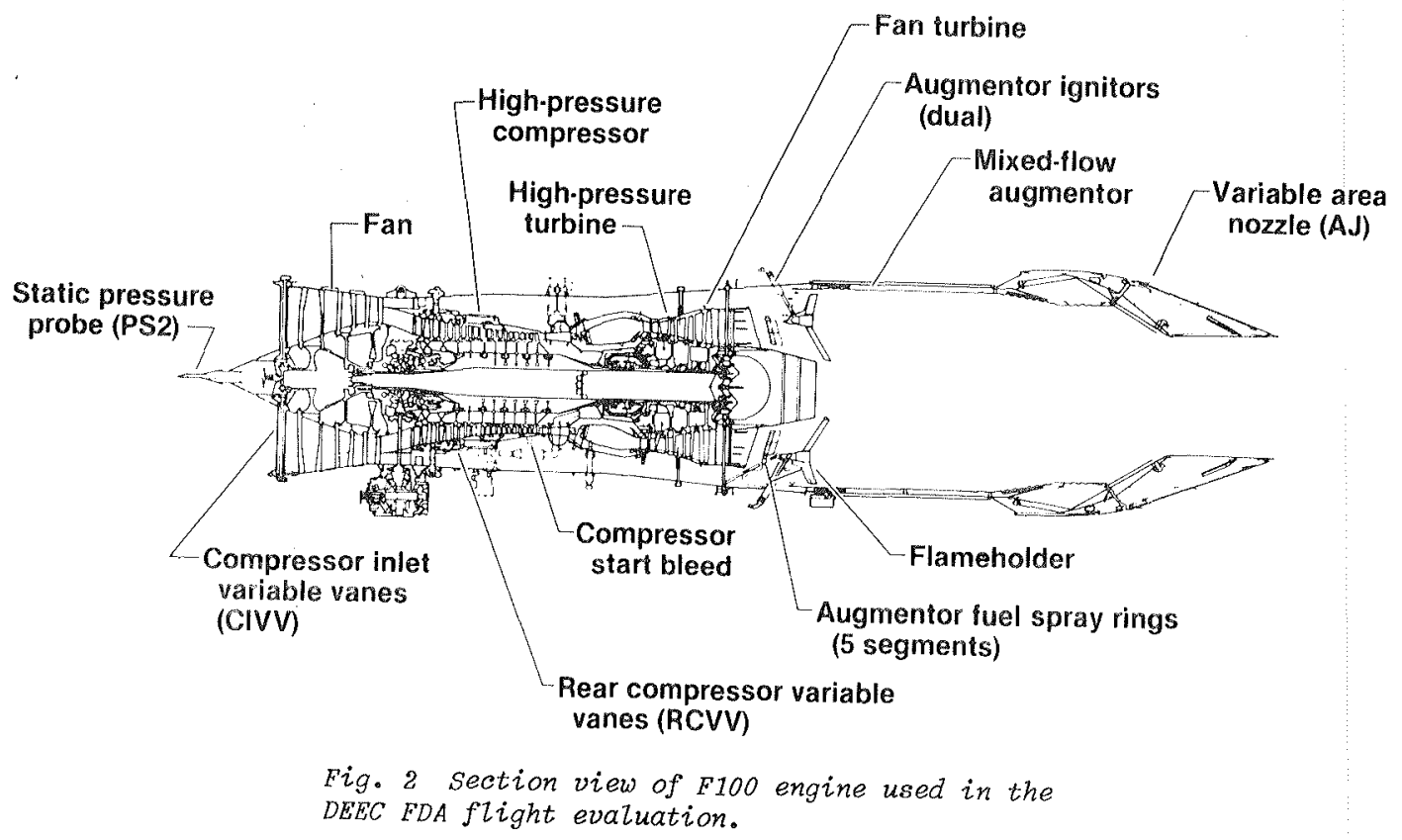




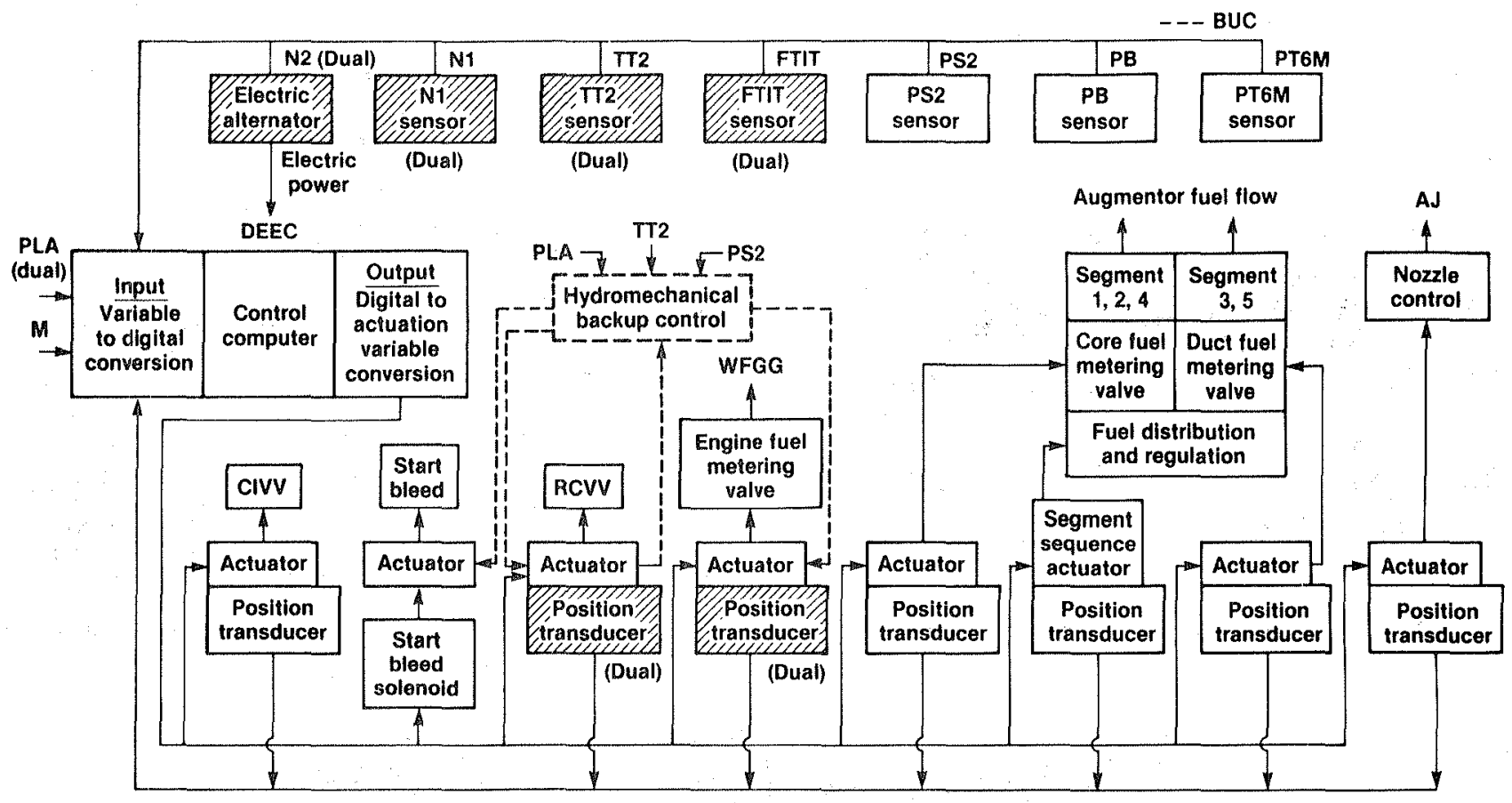

Fig. 3 schematic of DEEC control system.

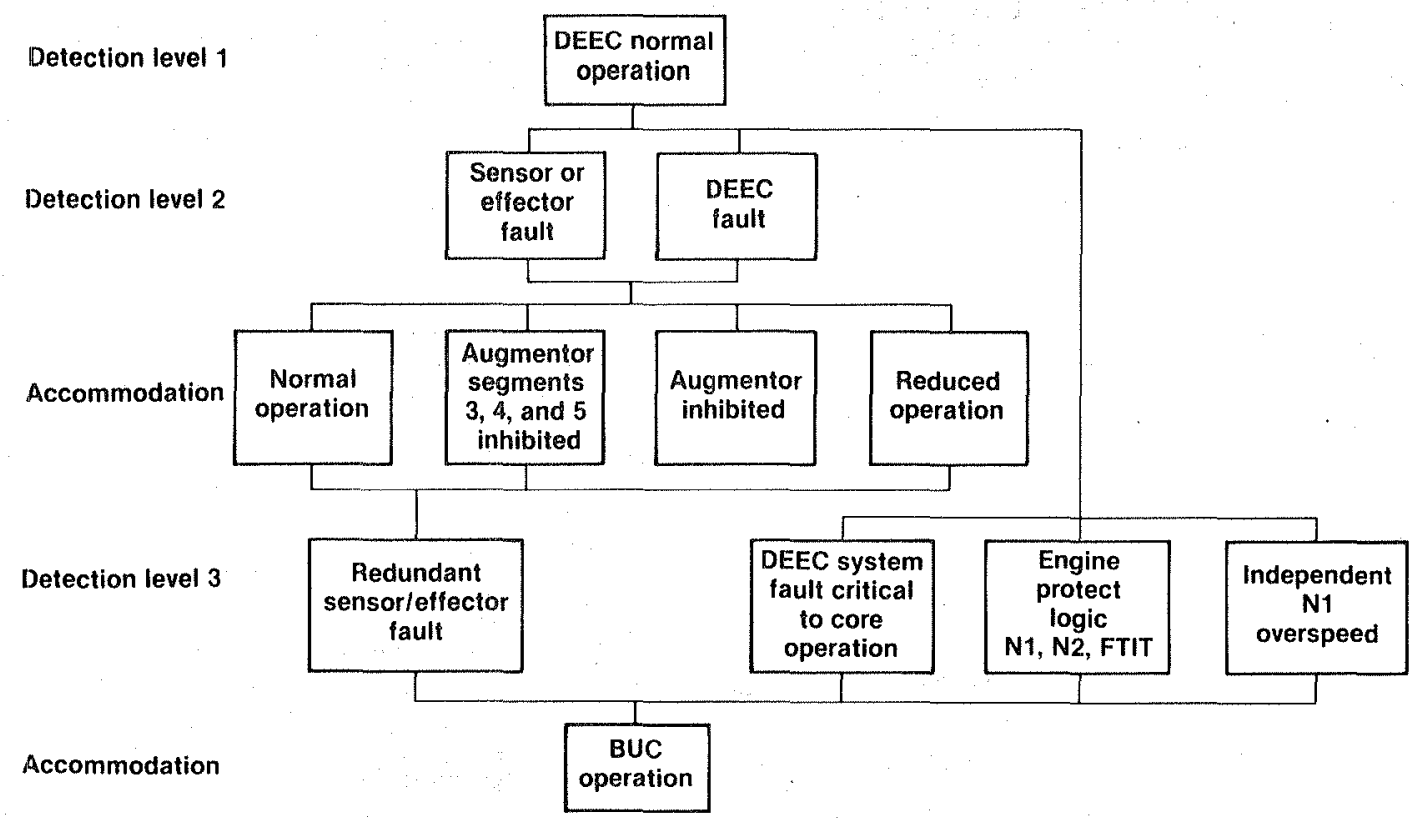

Fig. 4 Fault-detection and accommodation levels within the DEEC logic. 


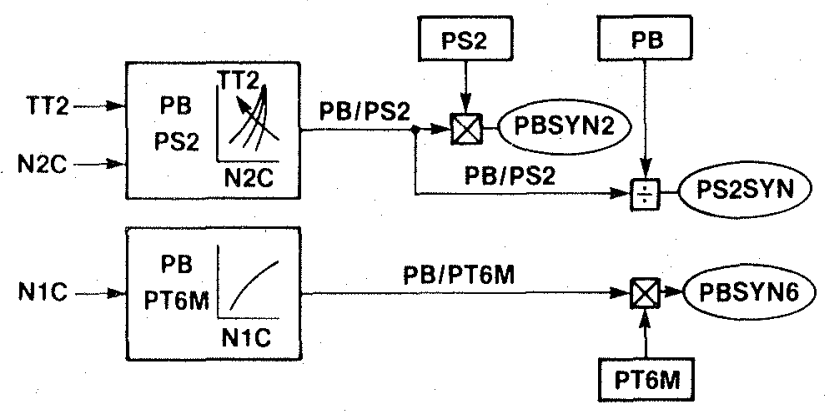

Fig. 5 Nonredundant pressure sensor logic.

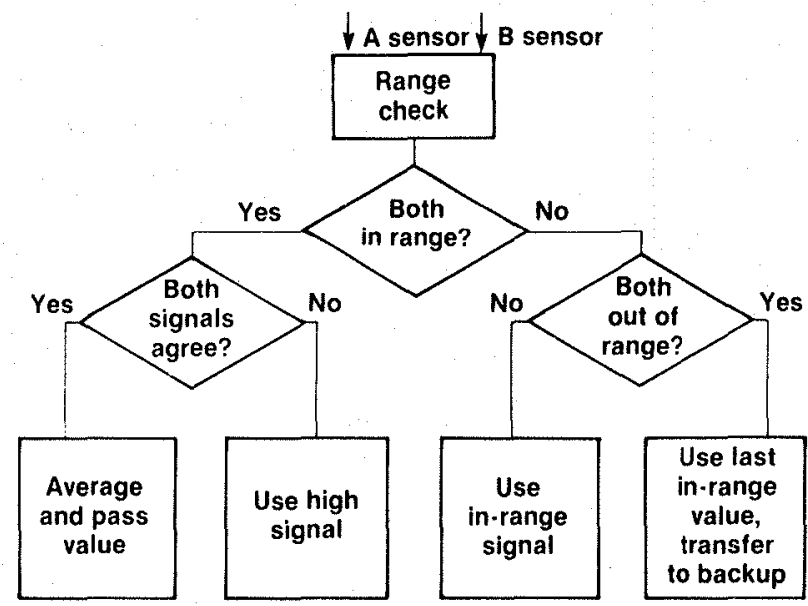

Fig. 6 DEEC FDA logic for redundant sensors.

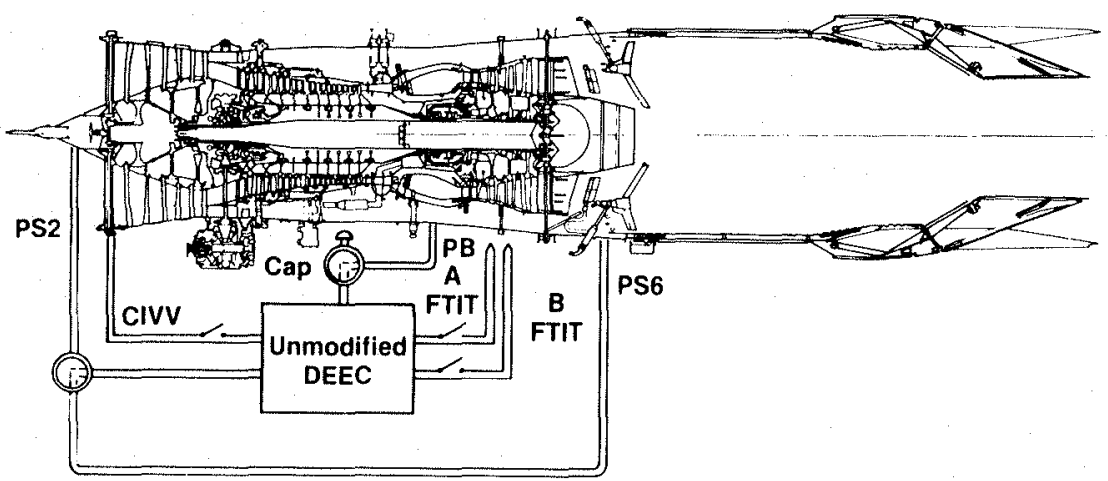

Fig. 7 DEEC engine - FDA modifications.

Sensor failures

O Steady-state power

口 Throttle transients

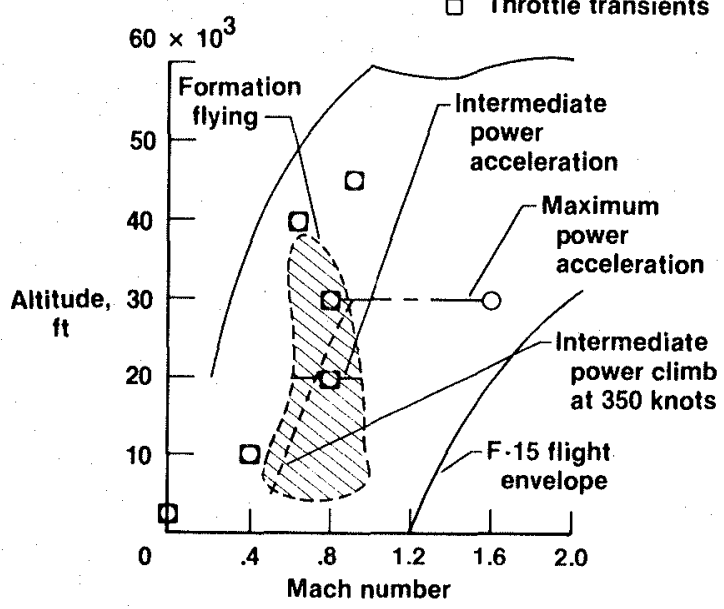

Fig. 8 DEEC - FDA test points. 

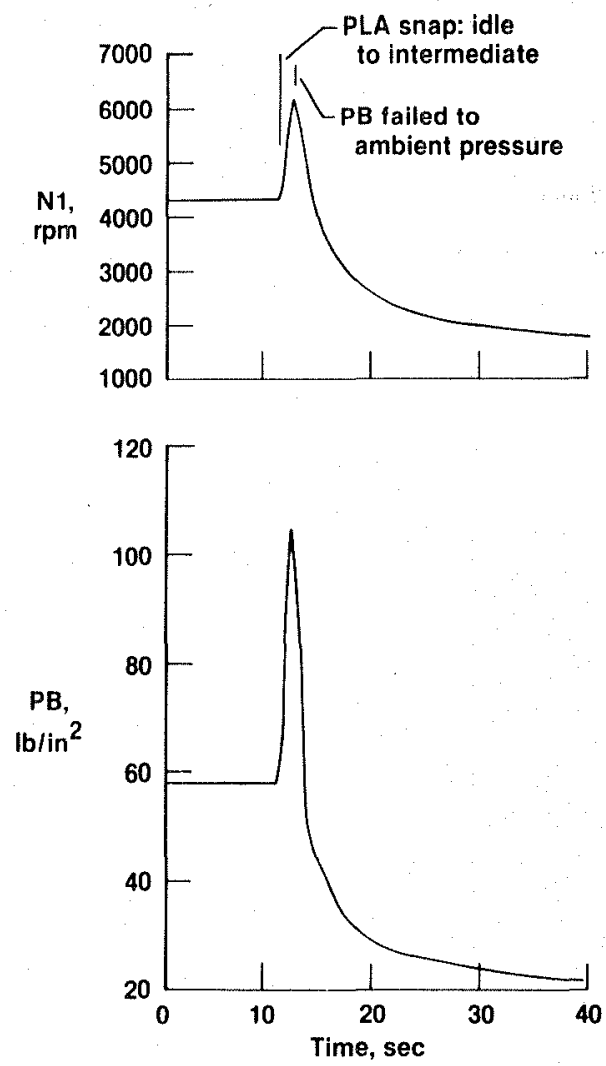

Fig. 9 Idle-to-intermediate throtthe transient with burner pressure failed to ambient. Ground test.

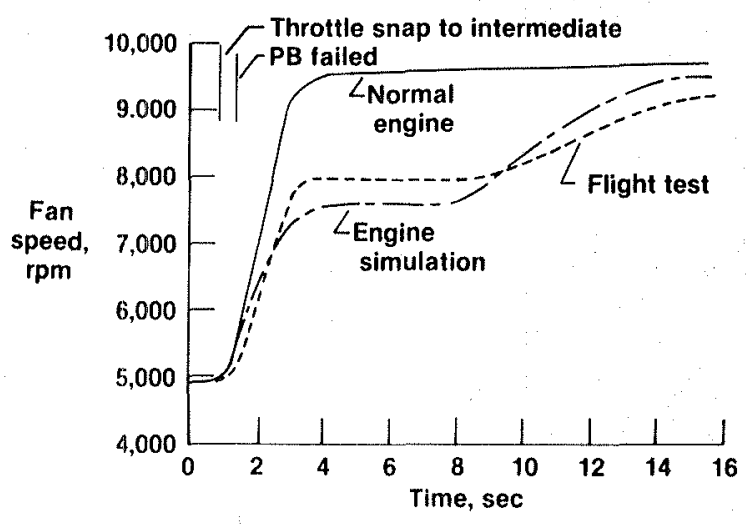

Fig. 10 Idle-to-intermediate throttle snap with burner pressure capped at $20,000 \mathrm{ft}$ and $0.8 \mathrm{M}$.
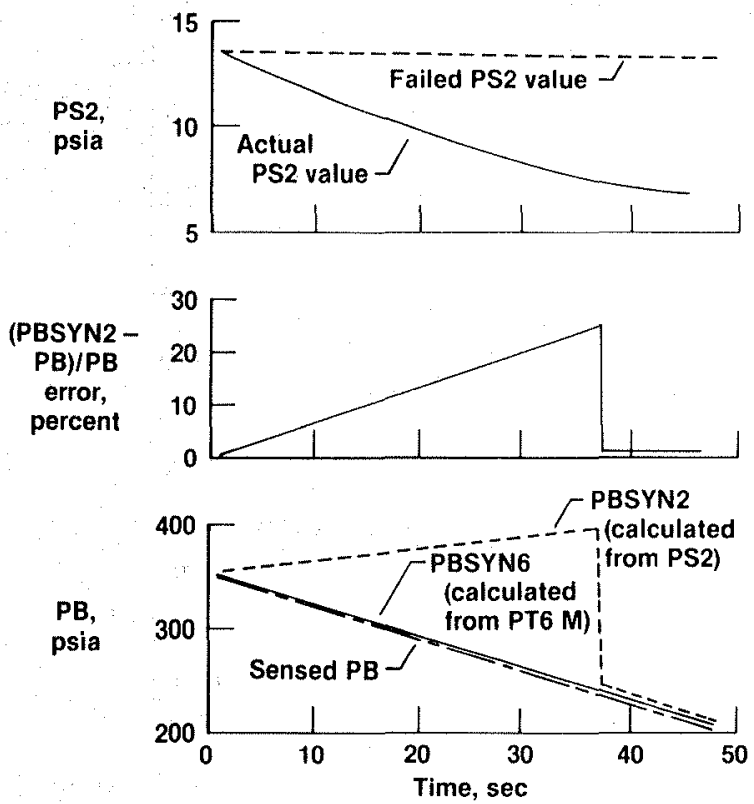

Fig. 11 Intermediate power climb from 5,000 to $30,000 \mathrm{ft}$ with PS2 capped at 5,000 ft.

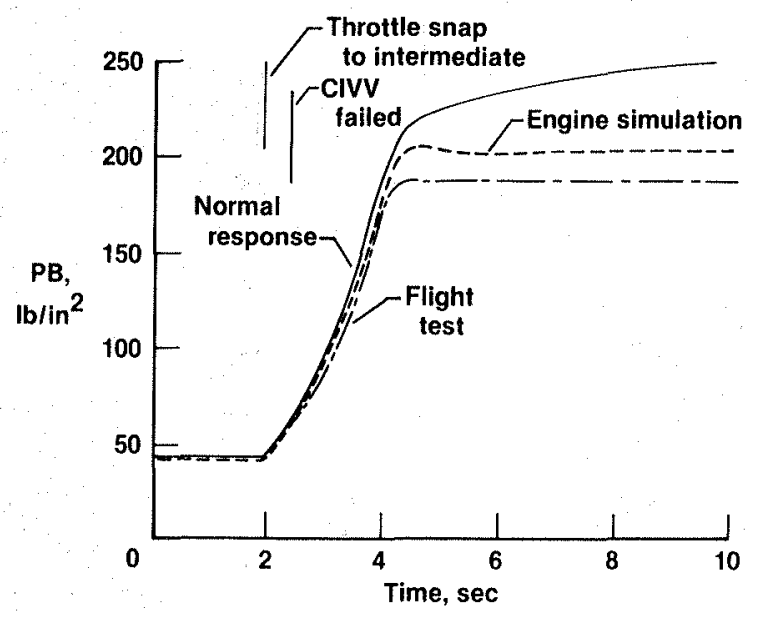

Fig. 12 Idle-to-intermediate throttle snap with CIVV failed, at $20,000 \mathrm{ft}$ and $0.8 \mathrm{M}$. 

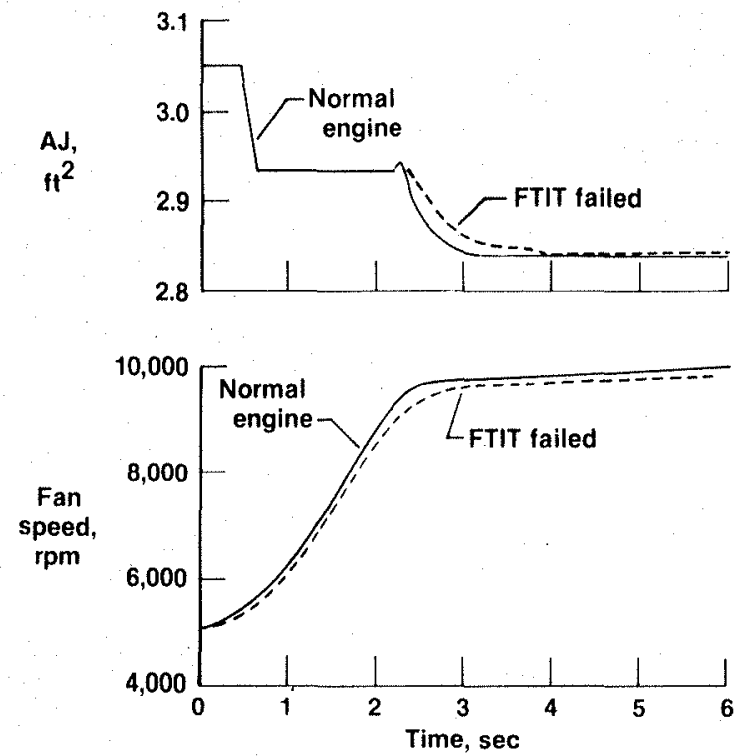

Fig. 13 Idle-to-intermediate throttle snap with ETIT failed, at $20,000 \mathrm{ft}$ and $0.8 \mathrm{M}$.
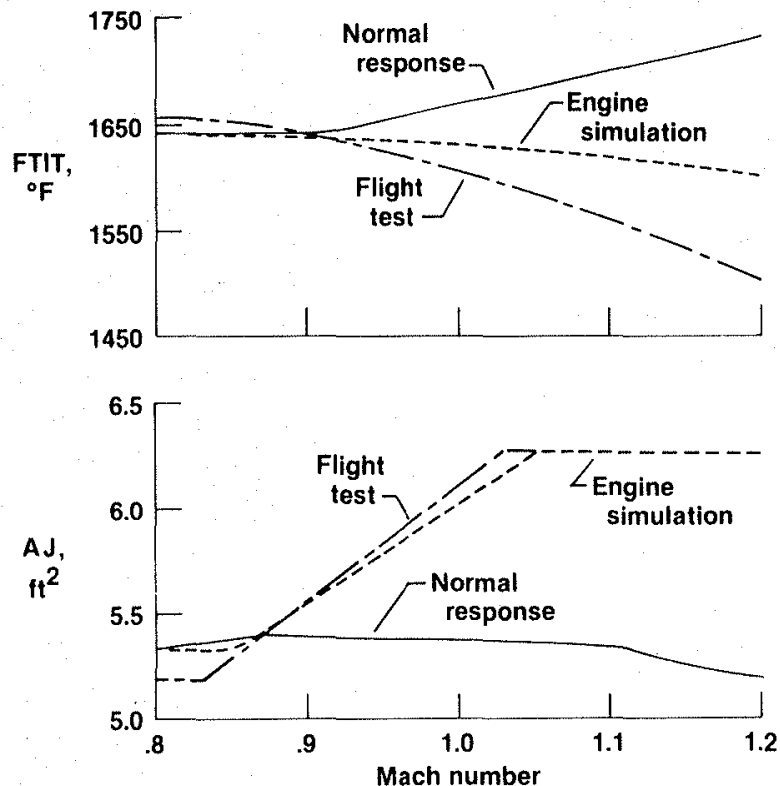

Fig. 14 Maximum power acceleration at $30,000 \mathrm{ft}$ with PS2 failed (capped) at $0.8 \mathrm{M}$. 


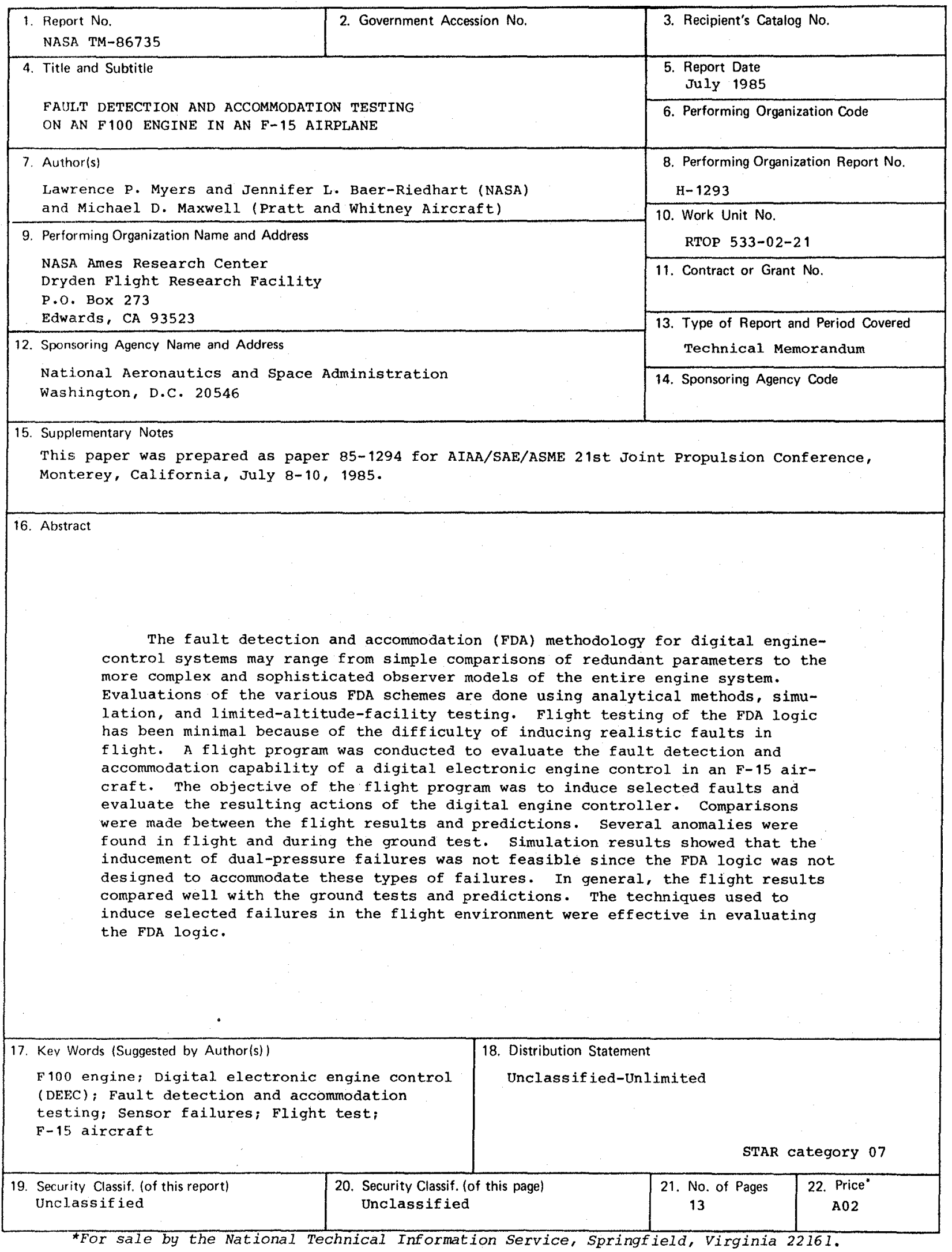




\section{End of Document}

